\title{
Dinámica de construcción territorial en los asentamientos del río Otún en Pereira (1950 2000): fenomenología a la territorialidad del sujeto habitante
}

Territorial Dynamics of Settlements Construction at Otún River in Pereira (1950 2000): Phenomenology of the Territoriality of Inhabitants

Julio César Murillo García ${ }^{1}$

Para citar este artículo, utilice el nombre completo así:

Murillo, J. C. (2015). Dinámica de construcción territorial en los asentamientos del río Otún en Pereira (1950-2000): fenomenología a la territorialidad del sujeto habitante. Perspectiva Geográfica, 20(1), 71-102.

\section{Resumen}

El presente artículo surge como resultado del análisis-interpretación a la dinámica territorial en los asentamientos informales ubicados sobre las márgenes del río Otún a su paso por la comuna Otún en la ciudad de Pereira, desde dos momentos nodales de su construcción: momento fundacional (1950) y momento de toma y apropiación de predios (2000). Como metodología se asume la fenomenología a la territorialidad cotidiana del habitante, explícitamente desde dos variables: contexto socioeconómico y vínculos territoriales. A partir de allí se consolidaron universos de análisis e interpretación sobre la territorialidad del sujeto que dan cuenta de fricciones

1 Licenciado en Ciencias Sociales de la Universidad de Caldas. Aspirante a Maestro en Geografía, convenio UPTC - IGAC. enguivuk1@gmail.com 
y/o conflictos espaciales con respecto a la política pública territorial del municipio de Pereira, en medio de la ejecución de programas y proyectos de gestión y planificación territorial con un denotado carácter hegemónico. Con ello se despeja un panorama crítico reflexivo alrededor de la implementación de estas políticas y al desarrollo sostenible territorial.

Palabras clave: desarrollo sostenible territorial, sujeto habitante, territorialidad cotidiana, territorialización.

\begin{abstract}
This article results from the analysis and interpretation of the territorial dynamics within the informal settlements located at the riverside in the Otun locality in Pereira. The analysis refers to two nodal moments of the construction of these informal settlements: its foundation (1950), and the land seizures (2000). Methodologically, the study is a phenomenology of the inhabitant's daily territoriality from two variables: the socio-economic context, and territorial ties. From this phenomenology, the analysis and interpretation of the subject's territoriality reveals tensions and/or territorial conflicts in regards to Pereira's territorial public policy. These conflicts have taken place in the midst of the implementation of programs and projects of territorial planning that have a manifest hegemonic character. In this way, the article calls for a critical reflection about the implementation of these public polices, and about sustainable territorial development.
\end{abstract}

Key words: territorial sustainable development, subject inhabitant, everyday territoriality, territorializing. 


\section{Introducción}

Abordar el análisis-interpretación sobre las dinámicas de construcción de territorio en las orillas del río Otún a su paso por la Comuna Otún en la ciudad de Pereira desde dos de sus momentos nodales, 1950 y 2000, implicó en este artículo el posicionamiento de una dialéctica social, en la que relaciones y fuerzas de poder confluyen sobre el espacio con el objeto de apropiar y/o controlar procesos sociales que se dan al interior de este. A partir de allí, tomó importancia el sujeto habitante desde su territorialidad cotidiana, al ser relación y fuerza que apropia y controla procesos tan concretos en la zona como son las dinámicas de crecimiento y expansión de la ciudad, las formas de ocupación y los valores dados al suelo. Igualmente toman importancia bajo esta dialéctica, las fricciones y conflictos derivados del encuentro con otras relaciones y fuerzas de poder, que para el sujeto habitante en las orillas del río Otún están representadas por el proyecto de gobernanza de la ciudad.

El enfoque fenomenológico permitió explorar con profundidad, la territorialidad de este sujeto habitante (Lindón, 2009) en dos momentos nodales de territorialización (dada la complejidad de abordar 50 años de construcción territorial): por un lado el momento nodal fundacional en el que numerosas familias, llegadas en su mayor parte del campo, arriban a la zona desarraigadas por la violencia (década del cincuenta $)^{2}$, dando inicio a procesos territoriales que hasta hoy se mantienen; igualmente momento nodal de apropiación de predios del municipio, que inicia hacia el 2000 con la ocupación que hacen de estos, pobladores sin techo que reivindican su lucha alrededor de la vivienda. Percepciones manifiestas tanto en la memoria sobre lo que fueron sus condiciones socioeconómicas y las del territorio que hoy ocupa, como en las narrativas sobre los vínculos territoriales que se consolidan a través de la casa y de la subsistencia.

Se posiciona con esto al interior de la investigación el sujeto habitante, el sujeto espacializado como "motor de la vida social" (Lindón, 2009, p. 10), que a través de su

2 "A finales de la década de los 40, debido a un proceso migratorio por motivos de violencia, llegaron a la ciudad personas procedentes del Valle del Cauca, Antioquia, Tolima, y otros Municipios Caldenses. Debido a este proceso migratorio se empezó a poblar la comuna de una forma espontánea, sin planificación e insuficiencia de infraestructura de servicios" (SPM, 2010, p. 5). 
actuar en el mundo, de su habitar, "hace y modela los lugares y al mismo tiempo, recibe el influjo de los lugares que habita" (p. 10). Lugares que modela y lo modelan. Desde esta óptica, la Territorialización que es construcción de territorio, permite establecer dinámicas tangibles y significativas del sujeto con su espacio; dinámicas de empoderamiento y control gradual de procesos sociales, bajo contextos socioeconómicos específicos, que trascienden territorialidad en tanto "campos de representación" (Haesbaert, 2013, p. 27), a partir del acumulado de vivencias y emociones de un sujeto que habita permanente su territorio.

La fenomenología, desde la percepción, como herramienta metodológica de análisis espacial, permite acercar este dato primario, al campo de las representaciones que emergen desde la memoria y que configuran discursos y actos en el poblador que habita las orillas de río. Abordarlo exige linderos conceptuales que se encuentran subsecuentemente en la casa como refugio y en la subsistencia como red, asociados a sus correlatos. De esta manera la casa-refugio (Bachelard, 1975) se define como "realidad profunda de cada uno de los mati- ces de nuestro apego" (p. 34). Casa que "suplanta contingencias, multiplica sus consejos de continuidad (...) lo sostiene a través de tormentas del cielo y de las tormentas de la vida. Es cuerpo y alma. Es el primer mundo del ser humano" ( $p$. 37). Casa-refugio, que es protección ante los avatares que la realidad misma hace emerger; es un adherente al territorio que el sujeto "sensibiliza (...) (que) vive en su realidad y en su virtualidad" ( $p$. $35)$.

Igualmente la subsistencia-red (Haesbaert, 2013) permite comprender el arraigo territorial desde la interacción de fijos y flujos que transversalizan los desplazamientos constantes y cotidianos, "La gente está transitando todos los días por redes que articulan pequeñas zonas, las cuales forman parte de territorios-redes que esa misma gente está construyendo" (p. 22). Una intensa movilidad (p. 32) que vista como subsistencia económica impone flujos necesarios de territorialización, puntos en red que hacen parte de la vivencia tangiblesignificativa del sujeto asentado sobre las orillas del río.

En este marco, donde el mundo de la vida del poblador es elemento 
base de reflexión y análisis, donde el territorio vivido del sujeto habitante proporciona los datos primarios de análisis e interpretación, se configura el escenario de reflexión crítica sobre las implicaciones que genera la política pública territorial de la ciudad de Pereira sobre la territorialidad del sujeto habitante que construye su hábitat en las orillas del río Otún (en la doble condición temporal de nodo que se esbozó anteriormente). Aquí no se hace problemático per se el hecho de producir espacio, sino las condiciones inequitativas o los vacíos sobre los que se erige esa producción (de allí su marco en las relaciones sociales de poder). El sujeto que habita estos asentamientos ha construido valores y significados sobre el territorio que se hace necesario conocer en perspectiva de una planificación incluyente y equitativa, democrática si se quiere.

Aunque existe una declaratoria de suelos de protección ambiental emanada del acuerdo 18 de 2000, norma que reglamenta el Plan de Ordenamiento Territorial Municipal (POTM) de la ciudad (necesaria para los planteamientos de sostenibilidad y conciencia medio ambiental) en el marco de la Ley 388 de 1997, o el Decreto Ley 1541 de
19783; otra sobre el mejoramiento progresivo de lo que se ha denominado asentamientos sub- normales ${ }^{4}$ definida para el mejoramiento de la calidad de vida de los habitantes; y otra en el marco de la ampliación del sistema estructurante de espacio público ${ }^{5}$; no existe una política que integre las fricciones que aún persisten sobre el poblador, sobre su insatisfacción social, sobre sus necesidades básicas insatisfechas (NBI); fricciones conflictivas que la política pública territorial debe resolver dado su "énfasis en el crecimiento económico (...) (que) prescinde generalmente de otras dimensiones (...) parte esencial de una buena vida" (Gutiérrez, 2012, p. 235).

3 Mediante el cual se reglamentan las normas relacionadas con el recurso de aguas en todos sus estados en el territorio colombiano y en especial en lo correspondiente a la gestión que ejercen los municipios frente al "dominio de las aguas, cauces y riberas, y normas que rigen su aprovechamiento sujeto a prioridades, en orden a asegurar el desarrollo humano, económico y social, con arreglo al interés general de la comunidad".

4 Contemplado en la ley marco para el ordenamiento territorial (Ley 388 de 1997), en los Artículos 3 (función pública del urbanismo), numeral 4; 8 (acción urbanística); 10 (determinantes de los planes de ordenamiento, numeral 5); 31 (suelo urbano). Igualmente en el POT de la ciudad de Pereira, Artículo 16 (políticas a mediano plazo sobre uso y ocupación del suelo urbano y de expansión urbano).

5 Ley 388 de 1997, Artículos 34 (suelo urbano) y 37 (espacio público en actuaciones urbanísticas). Y en el POT de Pereira de 2000, Artículo 16 (políticas a mediano plazo sobre uso y ocupación del suelo urbano y de expansión urbano). 
Ello corresponde a elementos de fricción-tensión sobre los cuales subyace la hegemonía que produce socialmente el espacio (Santos, 2000); hegemonía asociada al ejercicio del poder político desde la gobernanza, entendida como espacio de control, de planeación y gestión, que "contiene límites (para Pereira la plataforma funcional ciudadregión), y que transmite la idea de cerramiento (...) está ligado a la idea de poder político, estatal (...) en todas las escalas" (Montañés y Delgado, 1998, p. 123), es decir, espacio controlado por la acción de agentes que lo producen, por relaciones de apropiación conflictiva. Una dialéctica de producción y reproducción "en conexión con las fuerzas productivas... (un espacio) elaborado por una voluntad y por un pensamiento colectivo" (Lefebvre, 2000, p. 89); un espacio-ciudad producido en la convergencia "indisoluble, solidaria y también contradictoria, de sistemas de objetos y de acciones" (Santos, 2000, p. 54).

El habitante informal, que levantó sus ranchos en la década del cincuenta dominando el territorio y ampliando sus campos de representación, así como el habitante informal de la toma y apropiación de predios que apenas inicia; sienten la fricción de este proyecto sobre su territorialidad, sobre cada uno de los campos de representación que lo vinculan a un territorio y a las relaciones de tipo social que allí se despliegan. La hegemonía planifica y ordena al margen de sus condiciones particulares y de sus necesidades más inmediatas. El espacio social hegemónico de Pereira se viene produciendo desde la década de los noventa, bajo contextos de competitividad a escala mundo; contextos de regionalización que configuran centralidades-clúster para el capital (Zambrano \& Bernard, 1993; Barón, 2002; Martínez, 2010); contexto de convergencia sobre criterios vocacionales de ciudad: como centro de negocios y de servicios de alcance regional; como enclave turístico proyectado nacional e internacionalmente; como polo de desarrollo industrialagrícola; y como territorio líder en sostenibilidad ambiental (Acuerdo 18, 2000, p. 5).

El problema de investigación se sintetiza en la necesaria comprensión de la territorialidad cotidiana del sujeto habitante, desde los propios contextos que la originan y desde los fuertes vínculos que lo entrelazan; con ello se tiene un 
insumo analítico-interpretativo que posibilita al interior de la investigación, reflexiones críticas encaminadas a posicionar otras dimensiones en la configuración de políticas públicas de ordenamiento territorial. Reflexiones que orbitan alrededor de lo que Gutiérrez (2012) denomina desarrollo sostenible territorializado, y que el autor define como "articulación $\mathrm{y}$ equilibrio entre las estructuras y los elementos sociales, económicos, ambientales y políticos institucionales" (p. 242) y que incluye entre otros elementos, "un nuevo modelo de vida (...) una propuesta ética y política (...) la reorientación del sentido y direccionalidad de la actividad económica (...) la equidad territorial para el buen vivir (...) y activa participación de la población en las decisiones fundamentales" (p. 25).

\section{Ubicación del problema}

El problema de investigación está centrado sobre los barrios San Juan de Dios, Risaralda y Salazar Robledo, tres barrios que hacen parte de la Comuna Río Otún en la ciudad de Pereira ubicada hacia el borde norte de esta ciudad. Barrios sobre los cuales se contextualizan espacialmente las dinámicas de trans- formación definida por el proyecto de ciudad-región; las dinámicas propias de la Comuna Otún como fragmento funcional del proyecto de ciudad ${ }^{6}$; y las dinámicas del río Otún, como fragmento estructurante del proyecto ambiental de la ciudad $^{7}$ (Ver Figura 1).

\section{En relación con la ciudad ${ }^{8}$, como $^{2}$} espacio urbano definido en el POT de 2000 (Acuerdo 18 de 2000): Los asentamientos analizados (barrios Risaralda, San Juan de Dios y Salazar Robledo) se ubican sobre el borde norte que representa el río Otún para el perímetro urbano de la ciudad y sobre, la frontera infranqueable de pendientes entre $50^{\circ}$ y $100^{\circ}$ de inclinación, que genera un gran "Telón Verde" (CAR-

6 En este sentido, el artículo 66 del Acuerdo 18 de 2000 plantea sobre la zona de planificación Otún: "Constituir este fragmento del territorio como una zona estratégica de especialización funcional (...) que garanticen el desarrollo y consolidación de algunos sectores" (p. 35).

7 El Artículo 80 del Acuerdo 18 de 2000 plantea: "El Sistema Ambiental Estructurante del Municipio de Pereira comprende el conjunto de los ecosistemas estratégicos de importancia ambiental" (p. 38).

8 La ciudad se encuentra ubicada en el Departamento de Risaralda, sobre la cordillera central, en el pie de monte de la cara occidental de esta, a una Latitud de $4^{\circ} 48^{\prime} 30.51^{\prime \prime} \mathrm{N}$ y una Longitud de $75^{\circ} 41^{\prime} 52.08^{\prime}$ W (CARDER, 2013). Hacia el Norte limita con los municipios de Dosquebradas, Santa Rosa de Cabal y Marsella; al Sur: Municipios de Ulloa (Valle del Cauca), Filandia y Salento (Quindío); al Oriente: con Anzoátegui, Santa Isabel, Ibagué (Tolima) y la zona de los nevados; y al Occidente: Cartago, Ansermanuevo (Valle del Cauca), Balboa, La Virginia (CARDER, 2002). 


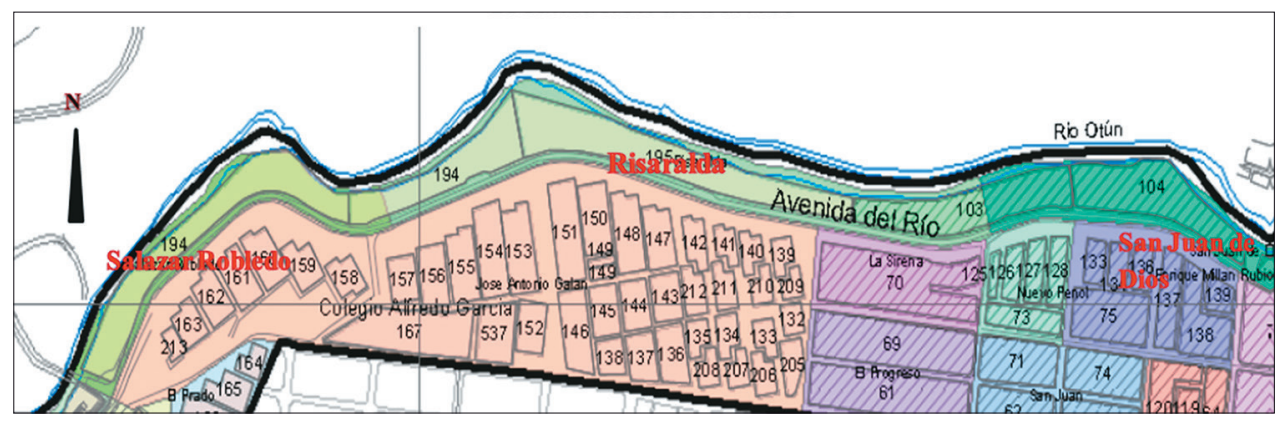

Figura 1. Barrios Risaralda, San Juan de Dios y Salazar Robledo

Fuente: Tomado de Mapa Zona de planificación urbana UP7, conformación de barrios (Secretaría operativa de sistemas de información SIGPER; escala 1: 5.000, 2010).

DER, 2010), perpendicular al curso del río (Figura 2). Esta localización con respecto a la ciudad, permite ubicar el lugar que ocupan los asentamientos de estudio como borde al interior del perímetro urbano, $\mathrm{y}$ como asentamientos de ocupación de suelos de protección ambiental municipal, dada la proximidad que se establece del asentamiento con el río y de la política ambiental que para el municipio se establece a partir de la implementación del POT de 2000 y su posterior revisión en 2006 (Artículo 40, Acuerdo 23, 2006). Igualmente permite ubicar la zona en proximidad al Clúster centro (Acuerdo 65, 2009), definiendo con ello dinámicas de territorialidad a partir de contextos socioeconómicos (ver interacción entre las Comuna Río y Comuna Centro (Figura 3).
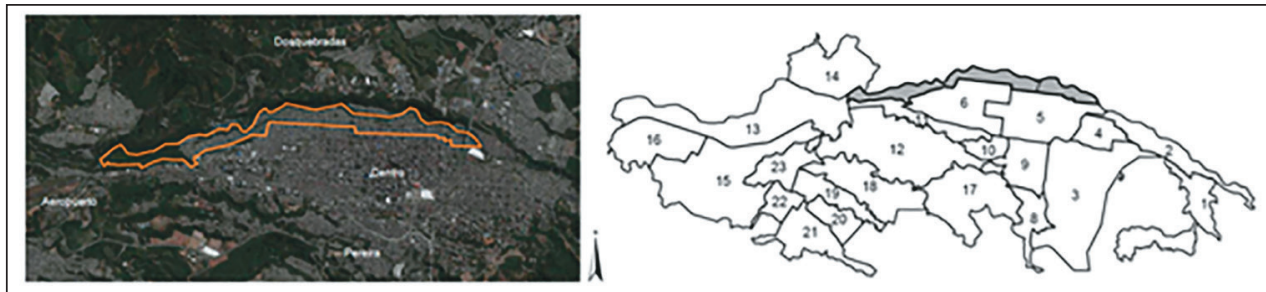

Figura 2. Localización UP7- Comuna río Otún, ciudad de Pereira. Diagnóstico unidad de planificación 7

Fuente: Secretaría de Planeación Municipal (2010). 


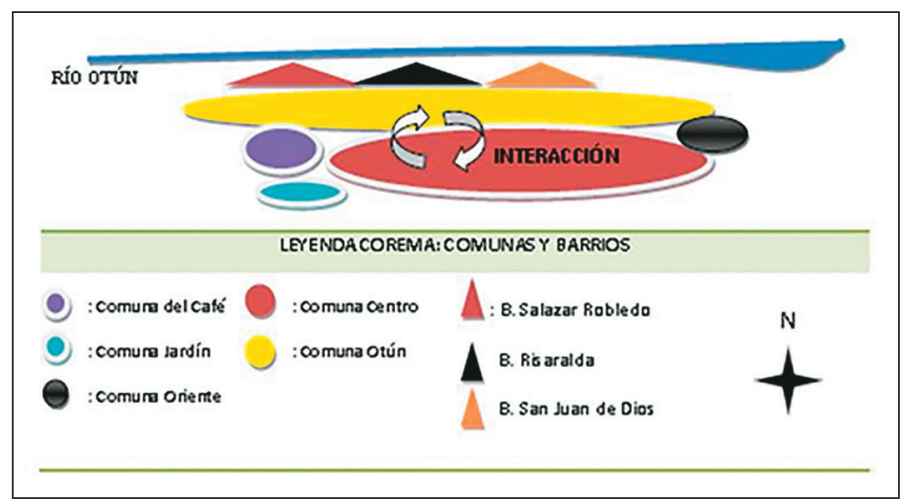

Figura 3. Corema Comuna Otún, Municipio de Pereira

Fuente: Elaboración propia a partir de mapa básico urbano - comunas (Secretaría operativa de sistemas de información SIGPER; escala 1:18000, según proyección de Gauss, zona 1).

En cuanto Comuna Otún': Esta delimitación permite comprender diferentes dinámicas alrededor de los tres barrios que son objeto de investigación: en primer lugar la condición limítrofe de la Comuna Otún con la Comuna Centro que define dinámicas de tipo socioeconómico al ser esta última la centralidad de mayor importancia en la ciudad (Acuerdo 65, 2009). De esta forma las actividades econó-

9 Esta Comuna hace parte de las 19 que conforman el perímetro urbano municipal; se encuentra localizada al norte de la ciudad entre el límite natural representado por el río Otún y, las comunas: "Centro" hacia el sur (con la cual limita en su mayor extensión); "Oriente" hacia el oriente; y "del café" y "jardín" hacia el occidente. Es una de las comunas más pobladas con 40.946 hab. (Según Censo 2005) y con mayor número de barrios (36 en total) (SIGPER, 2007). Igualmente la Secretaria de Planificación Municipal, en el "Informe técnico de estratificación socioeconómica del municipio de Pereira" (2011) determinó un total de 8.536 predios para esta comuna, de los cuales 1.303 (el $15.26 \%$ ) corresponden al estrato I; $2409(28,2 \%)$ al II; 3025 (35.4\%) al III; y $1799(21,1 \%)$ a los estratos 4,5 y 6. micas (formales o informales) y sociales de los pobladores que residen sobre estos asentamientos estarán ligadas en gran medida a esta centralidad, factor que se convierte en determinante a la hora de analizar los arraigos territoriales.

En segundo lugar, los datos de estratificación de la comuna permiten visualizar una concentración de población en los estratos 2 y 3 , que representan el $28,2 \%$ y el $35.4 \%$ respectivamente y que sumados con el estrato 1 arrojan un total de $78.86 \%$ de población sobre los estratos 1,2 y 3 , estratos que dicho sea de paso presentan la mayor insatisfacción de necesidades básicas, configurando así una comuna de alta densidad poblacional y conflictos sociales que según la Secretaría de Planeación Munici- 
pal (SPM, 2010) "se caracteriza por ser de uso residencial con una marcada tendencia para viviendas de estratos medios y bajos" (p. 9). Dicha estratificación focalizada en los barrios Risaralda, San Juan de Dios y Salazar Robledo, permite visualizar "poblaciones en estrato bajo-bajo que corresponde a los barrios ubicados en zonas de riesgo (...) poblaciones con altos niveles de pobreza y bajos niveles de participación ciudadana" (SPM, 2010, p. 9).

El Río Otúnn ${ }^{\mathbf{1 0}}$ : Al igual que la cuenca del río Consotá (al sur de la ciudad) el río Otún se constituye como un espacio estratégico para el proyecto vocacional de ciudad dada su biodiversidad. Con ello la vocación de enclave turístico $\mathrm{y}$ de liderazgo en sostenibilidad (Acuerdo 18, 2000) toma sentido

10 El río Otún es para el municipio de Pereira una cuenca estructurante, como abastecimiento de agua potable y como modelo económico de ciudad; su extensión (superficie de 480,61 Km2) va desde el Parque Nacional Natural de los Nevados (al oriente) donde encuentra su nacimiento en la laguna del Otún a una altura de (3980 $\mathrm{msnm})$; hasta su desembocadura sobre el río Cauca (al occidente) a una altura de (875 msnm) (Plan de Ordenamiento y Manejo de la Cuenca Hidrográfica, $\mathrm{POMCH}, 2008)$. Esta cuenca se compone de tres tramos, siendo la cuenca alta la de mayor biodiversidad al estar delimitada por parques y reservas naturales (PNNN; Santuario de Fauna y Flora Otún Quimbaya); la cuenca media que abarca todo el perímetro urbano de la ciudad por el norte; y la cuenca baja que transita por sectores rurales del municipio al occidente. en el marco de lo que el proyecto de Eco región denominó ciudad verde (CARDER, 2002) o ciudad bosque (Contraloría, 2009). De allí la importancia de este sistema estructurante ambiental, que comprende elementos de la sostenibilidad ambiental (protección de ecosistemas), de la sostenibilidad económica (desarrollo de actividades con énfasis en lo ecológico) y de la sostenibilidad social (disfrute de la ciudad y su paisaje, y disminución de riesgos asociados a lo natural) de la ciudad.

Con esto la cuenca del río en su extensión entra a ser objeto de ordenamiento por parte de autoridades municipales; los barrios, San Juan de Dios, Risaralda y Salazar Robledo, se verán sometidos a un proceso de transformación en el que primero se declara la zona como suelo de protección (Artículo 40, Acuerdo, 23 de 2006) ${ }^{11}$, posteriormente sus pobladores son reubicados y finalmente se somete el territorio a un proceso de planificación en el que intervienen aspectos paisajísticos, sostenibles (en lo social- ambiental) y funcionales en un marco de enclave económico de la región.

11 Este es el acuerdo mediante el cual se reglamentó la revisión del POTM de 2000 en la ciudad de Pereira. 


\section{Metodología}

Esta investigación configuró un interés analítico-interpretativo sobre la dinámica territorial que construye el sujeto habitante. Su abordaje se plantea desde la mirada fenomenológica a la territorialidad cotidiana, y propone como resultado una reflexión crítica sobre la política pública territorial, en el marco del desarrollo territorial sostenible. En esta vía la investigación hizo parte del extenso campo de la Geografía Humana, explícitamente el campo de la Geografía de la Percepción, que toma como principal referente al sujeto y su subjetividad como motor de la vida; igualmente se planteó en el campo de la Geografía Crítica en cuanto buscó reflexionar sobre el territorio en el marco de relaciones de poder que apropian y controlan procesos sociales sobre el espacio (Pillet, 2004). De esta forma se integraron metódicamente dos campos de investigación geográfica, en diferentes nodos de territorialización (1950-2000), sobre tres de los asentamientos que integran el paso urbano del río Otún en la ciudad de Pereira.

Sobre esta línea, se buscó consolidar una fase de investigación, que permitiera el análisis-interpreta- ción a la territorialidad del sujeto habitante desde su propia percepción, como marco de las representaciones que este consolida en contextos de tensión-conflicto con la política pública territorial racionalizada desde la gobernanza. De esta manera se definió la fenomenología como base de investigación, desarrollada a partir de dos etapas de trabajo. La primera de estas, proyectada como diagnóstico al problema planteado, buscó hacer un reconocimiento inicial de actores, contextos, acciones vividas, que conllevaran a establecer variables e indicadores. En este punto el uso de relatos en extenso (etnografía), el análisis documental (revisión documental) y la observación de campo (etnográfica) (Quintana-Peña, 2006) fueron técnicas de recolección definitivas.

Así para el diagnóstico, se desarrollaron entrevistas con cinco habitantes de la zona, definidos por su condición territorial nodal al estar asentados, históricamente o a partir la vigencia del POTM en el año 2000: tres habitantes históricos que ocupan el territorio desde 1950 (entrevistas Ancízar Murillo, Margarita García y Cecilia García) ${ }^{12}$, y, dos

12 Caracterizando cada uno de estos habitantes se debe decir que: el señor Ancízar Murillo representa 
habitantes que ocupan el territorio desde el nodo o momento de toma y apropiación de predios iniciada en el año 2000 (entrevista a Marina y Fabio García) ${ }^{13}$. Igualmente se llevó a cabo una revisión al plan de ordenamiento territorial municipal del 2000 y su posterior revisión en 2006, así como la caracterización que Martínez (2010) hace sobre los Planes de desarrollo 97-2007 en Risaralda. Y finalmente se exploró desde la posición como sujeto de investigación, "de manera sostenida y dinámica" (Quintana, 2006) circunstancias y momentos acaecidos sobre el territorio.

esa territorialidad del habitante histórico que nunca abandono su predio, que aún hoy lo conserva y habita; la señora Cecilia García, representa la territorialidad fragmentada, territorialidad del habitante que cedió su predio aceptando un tipo de reubicación en otra zona de la ciudad y que termina regresando sobre el mismo sector u otros aledaños a este; la señora Margarita García, representa esa territorialidad del sujeto que ya no habita de ninguna forma el territorio, que lo rememora desde su infancia y sus condiciones de vida inicial.

13 Caracterizando el sujeto de este nodo, ambos habitantes poseen una cualidad de liderazgo al interior de las comunidades que apropiaron predios. Frente a esto, el señor Héctor Fabio ostenta a 2015, una condición diferente de "invasor", tras haber obtenido un fallo de la corte suprema en el cual se dispone ordenar a la Alcaldía de Pereira (...) la verificación de la situación personal, familiar, social y económica, con el fin de establecer la alternativa oficial que lo incluya en un programa que se desarrolle en ese municipio, que satisfaga las normas mínimas para vivienda de interés social (sentencia T - 631/13). En cuanto la señora Luz Marina ya completa 9 años de ocupación del predio y aún se mantiene en la zona, esperando decisiones favorables para su condición.
Ya para la segunda etapa, se consolidaron variables de trabajo: definidas por el contexto socioeconómico del territorio (con sus respectivos indicadores: $\mathrm{NBI}^{14} \mathrm{e}$ informalidad territorial ${ }^{15}$ ), y los vínculos territoriales (con los indicadores: casa-refugio y redes de subsistencia). Sobre esta base, inicia el análisis-interpretación a la territorialidad del sujeto habitante en las orillas del río (Ver Tabla 1); para ello se tomó la entrevista etnográfica, desde el desarrollo de un amplio margen de estas (15 en total), en las que predomina el relato, la narrativa, la vivencia, los significados que posee el habitante sobre su territorio, sobre el área de estudio y sobre las dinámicas que se manifiestan; se plantearon revisiones sobre documentos, que coadyuvaron a situar el territorio en términos de producción social de agentes hegemónicos

14 La metodología de las NBI para el estudio de la pobreza en los países latinoamericanos fue propuesta por la CEPAL en los años 70 y tiene como principal objetivo identificar hogares y personas que no alcanzan a satisfacer un conjunto de necesidades consideradas indispensables (Feres, 2001, p. 114). Para el DANE (2005) este indicador expresa las características físicas de viviendas consideradas impropias para el alojamiento humano (...) a partir de ellos se constituye un compuesto, que clasifica como pobre o con NBI aquellos hogares que estén, al menos, en una de las situaciones de carencia expresada por los indicadores.

15 De acuerdo con Saldarriaga (Citado en Hernández, 2007), "la ciudad informal significa también que no está hecha por los organismos oficiales o por empresas o entidades que hacen parte de la formalidad como estructura básica de una sociedad. 
que lo producen y de conflictos a los que tiene lugar el encuentro con otras territorialidades ${ }^{16}$; finalmente se implementó la técnica de observación participante desde la cual se logra acercar "elementos invariables y constantes (...) eventuales o novedosos" (Quintana-Peña, 2006, p. 68) sobre la dinámica del espacio.

Tabla 1. Síntesis fase de investigación.

\begin{tabular}{|c|c|c|c|}
\hline \multicolumn{4}{|c|}{$\begin{array}{l}\text { Fase de investigación: Enfoque fenomenológico: } \\
\text { territorialidad cotidiana nodos (1950-2000) }\end{array}$} \\
\hline Variable & Análisis & Interpretación & Objetivos \\
\hline $\begin{array}{l}\text { Contexto } \\
\text { socioeconómico }\end{array}$ & $\begin{array}{l}\text { Condiciones sociales } \\
\text { y económicas del su- } \\
\text { jeto y del territorio; a } \\
\text { partir de la condición } \\
\text { NBI y de informalidad } \\
\text { que posee la zona. }\end{array}$ & $\begin{array}{l}\text { La vulnerabilidad } \\
\text { social del territorio y } \\
\text { del sujeto, en el mar- } \\
\text { co de planteamien- } \\
\text { tos territoriales de la } \\
\text { política pública. }\end{array}$ & $\begin{array}{l}\text { Determinar y analizar } \\
\text { el contextos de vul- } \\
\text { nerabilidad socioeco- } \\
\text { nómica del sujeto ha- } \\
\text { bitante y del territorio } \\
\text { que construye. }\end{array}$ \\
\hline $\begin{array}{l}\text { Vínculos } \\
\text { territoriales }\end{array}$ & $\begin{array}{l}\text { Significados que el } \\
\text { sujeto construye so- } \\
\text { bre su casa-refugio y } \\
\text { sobre redes de sub- } \\
\text { sistencia, en términos } \\
\text { económicos, sociales } \\
\text { y afectivos. }\end{array}$ & $\begin{array}{l}\text { Fuertes vínculos que } \\
\text { el habitante estable- } \\
\text { ce con su territorio y } \\
\text { las fricciones que de } \\
\text { allí derivan con la } \\
\text { política pública. }\end{array}$ & $\begin{array}{l}\text { Determinar y analizar } \\
\text { los significados que } \\
\text { definen el vínculo } \\
\text { territorial y la acción } \\
\text { del sujeto habitante. }\end{array}$ \\
\hline
\end{tabular}

Fuente: Elaboración propia.

De este modo a partir de los resultados obtenidos durante la fase fenomenológica, se definen tensiones y conflictos, derivados de la implementación de programas

16 En este sentido se seleccionaron una serie de documentos que contenían la política pública territorial del municipio, para ser analizados a profundidad: plan de ordenamiento territorial de 2000 y su posterior revisión en 2006 (segunda revisión); Ordenamiento Territorial para el Desarrollo Sostenible en la Eco Región del Eje Cafetero, 2002; Plan de ordenamiento ambiental de la cuenca hidrográfica del Río Otún, 2008; Unidad de Planificación No. 5 "centro", de 2009; Diagnóstico de la zona de planificación 7 "río Otún", de 2010; Acuerdo de manejo para el área del parque lineal río Otún, 2010. y proyectos de gestión y planificación territorial, sobre la territorialidad del sujeto habitante; lo que permitió plantear interrogantes sobre el mundo de la vida (reflexión) desde los significados desiguales-asimétricos que de este mundo fueron observados (crítica), y desde el posicionamiento de otros discursos y otros paradigmas de la política territorial, que se sintetizan en la propuesta de desarrollo sostenible territorializado de Gutiérrez (2012). Así el sujeto que habita las 
orillas del río históricamente (proveniente del nodo fundacional) se ve sometido a la fricción que le impone el programa de reubicación y la declaratoria de suelos de protección al sostener vínculos, que desde su percepción y criterio, no son tomados en cuenta por los planificadores; igualmente el sujeto que toma y apropia predios del munici- pio (segundo nodo), es friccionado por la inminencia del desalojo, al ser considerado "invasor" por entidades públicas como control físico (de la secretaría de gobierno municipal) y por los conflictos socioeconómicos que se profundizan desde la NBI. (Ver Tabla 2. Relación sujeto-política pública).

Tabla 2. Relación sujeto-política pública

\begin{tabular}{|c|c|}
\hline \multicolumn{2}{|c|}{ Relación acciones frente al territorio: sujeto habitante-política pública } \\
\hline Sujeto habitante & Política pública \\
\hline $\begin{array}{l}\text { Frente al territorio: } \\
\text { - Pérdida de vínculos y redes de } \\
\text { territorialización } \\
\text { - Percepciones sobre la desigualdad de } \\
\text { las políticas públicas y la acción de } \\
\text { gobernanza }\end{array}$ & $\begin{array}{l}\text { Frente al territorio: } \\
\text { - Construcción de plataforma funcional } \\
\text { - Construcción de sistemas estructurantes } \\
\text { - Consolidación de proyecto de región }\end{array}$ \\
\hline $\begin{array}{l}\text { Frente a planes y proyectos: } \\
\text { - Ante la reubicación: como política que } \\
\text { subvalora su predio; como parte de } \\
\text { políticas engañosas; como oportunidad } \\
\text { de mejoramiento } \\
\text { - Ante la declaratoria de suelos de } \\
\text { protección: como necesaria tomando en } \\
\text { cuenta las necesidades de la población; } \\
\text { el riesgo como probabilidad lejana. }\end{array}$ & $\begin{array}{l}\text { Frente a planes y proyectos: } \\
\text { - Declaratoria de suelos de protección } \\
\text { - Reubicación de predios (dimensión } \\
\text { social-ambiental) }\end{array}$ \\
\hline
\end{tabular}

Fuente: Elaboración propia.

A partir de la obtención de información primaria/secundaria, que proporcionó cada una de las técnicas de recolección de información que sustentan esta investigación, se adelantó el procesamiento de datos, la clasificación de relatos según las variables definidas para ello y su análisis-interpretación a la luz de las fricciones-tensión definidas entre el sujeto y la política pública territorial; el diálogo intertextual, cruzado y comparativo de la base documental, y de esta con 
la realidad de sujeto (intra y transtextualidad); y finalmente la validez de lo observado a partir de un ejercicio reflexivo que involucra la experiencia directa, los marcos de significación previos del sujeto investigador y los resultados de las técnicas empleadas.
De este modo se consolidó una metodología de trabajo, que integra unos métodos, técnicas de recolección, unos procedimientos y unas variables, que visto integralmente, se sintetizaron así (Ver Tabla 3).

Tabla 3. Síntesis método, técnicas y procedimientos de investigación

\section{Método, técnicas y procedimientos}

Determinar los contextos y vínculos territoriales que definen la territorialidad del sujeto habitante en los asentamientos del río Otún de la ciudad de Pereira durante los nodos 1950-2010

\begin{tabular}{|c|c|c|c|c|}
\hline Método & Técnica & Procedimientos & Variables & Resultado \\
\hline 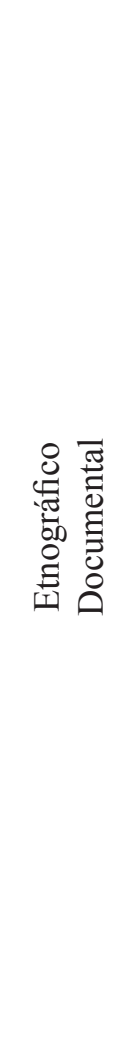 & $\begin{array}{l}\text { Recolección } \\
\text { de narrativas } \\
\text { a través de } \\
\text { entrevistas } \\
\text { con: } \\
\text { Habitantes } \\
\text { históricos del } \\
\text { lugar y nuevos } \\
\text { habitantes que } \\
\text { toman predios. } \\
\text { Observación } \\
\text { participante e } \\
\text { interactiva de } \\
\text { campo. } \\
\text { Revisión } \\
\text { documental } \\
\text { sobre política } \\
\text { pública } \\
\text { territorial del } \\
\text { municipio y la } \\
\text { región. }\end{array}$ & $\begin{array}{l}\text { Caracterizar- interpretar } \\
\text { información sobre varia- } \\
\text { bles: } \\
\text { - contextos del sujeto y } \\
\text { del territorio: carac- } \\
\text { terizar las condiciones } \\
\text { socioeconómicas que } \\
\text { posee el sujeto y el } \\
\text { territorio (entrevistas, } \\
\text { documentos, observa- } \\
\text { ción). Interpretación } \\
\text { sobre condiciones de } \\
\text { vulnerabilidad. } \\
\text { Vínculos de la casa-re- } \\
\text { fugio y la subsisten- } \\
\text { cia red: caracterizar } \\
\text { dimensiones sociales, } \\
\text { económicas y emotivas } \\
\text { que vinculan el habitante } \\
\text { (entrevistas- observa- } \\
\text { ción). Interpretación de } \\
\text { significados materiales- } \\
\text { simbólicos de la casa- } \\
\text { refugio. }\end{array}$ & $\begin{array}{l}\text { Contexto } \\
\text { socioeco- } \\
\text { nómico } \\
\text { territorial }\end{array}$ & $\begin{array}{l}\text { Esto permitió } \\
\text { determinar } \\
\text { contextos } \\
\text { socioeconómicos } \\
\text { del sujeto y su } \\
\text { territorio, así } \\
\text { como vínculos } \\
\text { que establece con } \\
\text { este. }\end{array}$ \\
\hline
\end{tabular}

Fuente: Elaboración propia. 
Frente a la población tomada, los barrios Risaralda, San Juan de Dios y Salazar Robledo, tenían según información de planeación municipal (CARDER, 1998) para 1997 un total de 259 viviendas evaluadas bajo condición de riesgo hidrológico e hidrotécnico ${ }^{17}$, siendo propuestas para su reubicación la totalidad de las mismas (Ver tabla 4). Para 2010, la Secretaría de planeación municipal a través del "diagnóstico a la unidad de planificación 7” (SPM, 2010), determina un total de 277 predios en la zona (Ver Tabla 5), 18 predios más en un margen de 13 años, con respecto a los datos presentados por CARDER.

Tabla 4. Riesgo y tipo de intervención en barrios de estudio

\begin{tabular}{|c|c|c|c|c|c|c|c|c|}
\hline \multirow{2}{*}{\multicolumn{4}{|c|}{ Viviendas clasificadas por tipo de riesgo }} & \multirow{2}{*}{\multicolumn{5}{|c|}{$\begin{array}{c}\text { Caracterización de la vivienda por } \\
\text { tipo de intervención }\end{array}$}} \\
\hline & & & & & & & & \\
\hline Barrios & Geotécnico & Hidrológico & Hidrotécnico & R1' & $\mathbf{R 2}$ & R3 & $\begin{array}{c}\text { Total } \\
\text { viviendas }\end{array}$ & $\begin{array}{c}\text { Población } \\
\text { en riesgo } \\
\text { (estimada) }\end{array}$ \\
\hline $\begin{array}{c}\text { San Juan } \\
\text { de Dios }\end{array}$ & & 99 & 2 & & 2 & 99 & 101 & 505 \\
\hline Risaralda & & 103 & & & 103 & & 103 & 515 \\
\hline $\begin{array}{c}\text { Salazar } \\
\text { Robledo }\end{array}$ & & 53 & 2 & & 41 & 14 & 55 & 275 \\
\hline
\end{tabular}

*R: Tipo de riesgo

Fuente: Elaboración a partir de CARDER (1998).

Tabla 5. Conformación predial barrios de estudio*

\begin{tabular}{|c|c|c|}
\hline \multicolumn{3}{|c|}{ Conformación predial por barrios } \\
\hline Barrio & N. $^{\circ}$ de predios & Porcentaje \\
\hline Risaralda & 119 & $2,8 \%$ \\
\hline Salazar Robledo & 86 & $1,80 \%$ \\
\hline San Juan de Dios & 72 & $1,50 \%$ \\
\hline
\end{tabular}

*La asignación porcentual corresponde a la participación del barrio con respecto a los datos globales de la Comuna Otún. Fuente: Elaboración propia con base en Secretaría de Planeación Municipal (2010).

17 Se debe aclarar que para los alcances del artículo no se obtuvieron datos relacionados con el número de viviendas reubicadas efectivamente, dado que se solicitó información al respecto, mediante radicado 29295 de 2014 , el cual no fue respondido por las entidades municipales. 
Esta discontinuidad en los datos CARDER-SPM, muestra un desajuste en la política de reubicación definida hacia el 2000 al incrementarse los asentamientos en vez de reducirlos como era el propósito inicial; igualmente evidencia porcentajes a considerar en términos de habitantes de la zona, que permiten dar cuenta de las magnitudes del fenómeno estudiado, los impactos del mismo y la necesaria reflexión sobre este; más cuando la misma SPM (2010) caracteriza estos asentamientos en categorías de vulnerabilidad alta, al considerarlos de estrato bajobajo en riesgo inminente.

Sobre esta base se consolidó para la investigación una población total de 20 sujetos, sobre los cuales se llevaron a cabo entrevistas semiestructuradas a profundidad, en un período de un año (2014). Igualmente se referencia la clasificación nodal territorial, al encontrar un sujeto habitante heterogéneo que corresponde a diferentes momentos de territorialización, y con ello a diferentes campos de representación. De allí que se tomaron habitantes del momento nodal 1950, por su condición histórica, para el análisis- interpretación de su territorialidad ( 7 personas en total); y habitantes del momento nodal 2000, por su condición directa de tensión- conflicto ante su situación de "informal" (8 personas en total).

\section{Resultados obtenidos}

Territorio construido: contexto, casa-refugio y redes de subsistencia

Como exploración al territorio construido (dinámica de territorialización) se obtuvo una fenomenología de la territorialidad del sujeto, en la cual se conjuga el contexto económico y social de este y de su territorio, con los vínculos territoriales que son su casa-refugio y las redes de subsistencia que extiende. Esta es una dialéctica en la que el sujeto establece sus propias reivindicaciones, significados y acciones sobre el territorio que ha construido, en oposición a los programas y proyectos de gestión y planificación territorial que implementa la política pública territorial de la ciudad de Pereira. Como dialéctica, esta territorialidad de lo cotidiano, proporciona elementos de interpretación y análisis a la sostenibilidad del territorio, como fundamento de los equilibrios y la equidad socioespacial en el marco de sociedades y proyectos políticos incluyentes. 
De esta manera, se obtuvo de diversos sujetos habitantes (desde la entrevista y la observación participante) relatos, contextos, vínculos, significados y perspectivas que situaron condiciones concretas del habitar y conflictos-tensión en este que son insumo de reflexión crítica. Así:

\section{Contexto socio-territorial en el momento fundacional:}

Como preámbulo a la exploración de los contextos socioterritoriales que transversalizan al sujeto; la narrativa permitió visualizar aspectos físicos del territorio ${ }^{18}$ sobre los cuales se define interactivamente la identidad social y económica: de esta manera la zona hacia la década de los cincuenta, hacía parte del sistema de inundación del río Otún ${ }^{19}$ (entre las actuales calles 19 y 38), configurándose como un lacustre, poco accesible, sobre el cañón del río Otún, en el que predominaban

18 La Comuna Río Otún surgió como una prolongación del centro de la ciudad hacia el Río. Es así como a fines de la década de los 40 y principios de los años 50 , la zona urbana del Municipio finalizaba en la carrera $4^{\text {a }}$. Lo que es hoy la comuna, eran solo potreros, rastrojos y lagunas (Secretaría de Planeación Municipal, 2010).

19 Donde dominaban innumerables escorrentías provenientes tanto de la vertiente norte, partes altas en las que se concentraba la expansión urbana de la ciudad (Carrera $7^{\circ}$ y $8^{\circ}$ con sus alrededores); como de la vertiente sur, desde las "pendientes entre 50 y $100^{\circ}$ de inclinación, (que) genera un gran "Telón Verde" (CARDER, 2010) y que traen escorrentías de lo que hoy es el municipio limítrofe de Dosquebradas. lagunas, quebradas y malezas: así lo describen los relatos ${ }^{20}$, "toda la 35 era rastrojos, no habían estas casas de ahí de la segunda (...) todo era en rastrojo, puro monte (...) todo lo que es Galán eran lagunas hasta la 31 con segunda" (Entrevista 1_1; min: 4:33); igualmente (la entrevistada) recuerda como, "lavábamos al frente en unos charcos porque como todo eso era lagunas al frente antes de hacer a Galán (...) esos charcos empezaban desde la segunda (...) hasta abajo hasta la orilla del río (...) eso todo eran rastrojos" (Entrevista 1_3; min: 0:05). Bajo esta condición física, proveniente de la memoria remota de los pobladores que desde el momento de fundación han ocupado estas orillas, se empezó a configurar un territorio, que en términos sociales, terminará constituyéndose como asentamiento informal en el marco de procesos invasivos y barrios autoconstruidos sobre las orillas del río; en términos económicos un territorio que brinda condiciones de asequibilidad al sujeto dado el valor de la tierra y de la vivienda (Tabla 6. Síntesis de relatos):

20 Son diferentes los relatos que dan cuenta de esta misma situación; entre ellos se tiene el relato del señor Ancizar Murillo (Entrevista 2_1; mins.: 1:30, 9:54); de la señora Limbania Pinzón Trejos (Entrevista 5_1; mins.: 7:34, 7:47); la señora Marleny Quintero (Entrevista 6_1; $\min : 26: 06)$. 
Tabla 6. Síntesis de relatos, $1^{\circ}$ momento entorno al territorio

\begin{tabular}{|c|c|}
\hline Condición social del territorio & Condición económica del territorio \\
\hline $\begin{array}{l}\text { "Esto aquí se hizo de guadua y por } \\
\text { encima eso era de...esto era una invasión, } \\
\text { plásticos por encima" (Entrevista } 2-1 \text {. } \\
\text { min: 0:36); "Esto fue invasión pero yo } \\
\text { no fui invasión yo vine cuando ya tenía } \\
\text { esto tres años de invasión" (Entrevista } \\
5 \text { 1: min: 1:27). "nosotros cuando } \\
\text { llegamos aquí llegamos fue buscando, } \\
\text { cierto, la orilla del río, ósea la Nación } \\
\text { porque el rio tiene veinticinco metros } \\
\text { de la orilla pa fuera... ya fue cuando ella } \\
\text { (Dueña) dijo que tenía la escritura global } \\
\text { (Entrevista } 2 \text { 1: min: } 8: 18 \text { ). }\end{array}$ & $\begin{array}{l}\text { "A nosotros nos tocaba casita en San Camilo } \\
\text { de material pero a mamá le dio miedo pagar } \\
\text { porque como ella era la única que trabajaba (...) } \\
\text { entonces mamá no quiso meterse en esas casas } \\
\text { porque le daba miedo que nos quedáramos en } \\
\text { la calle" (Entrevista; } 1 \text { 1: min: } 5: 48 \text { ). } \\
\text { Cuando eso uno bien pobre hermano eso hace } \\
\text { mucho tiempo (...) por aquí habemos personas } \\
\text { hermano que hablando francamente, que si } \\
\text { desayunamos no comemos, no almorzamos pa } \\
\text { uno meterse en una deuda bien verrionda (...) } \\
\text { pues que uno tuviera dos mil viviéramos más } \\
\text { arriba"21 (Entrevista } 2 \text { 1: min: } 17: 23 \text { ). }\end{array}$ \\
\hline
\end{tabular}

Fuente: Elaboración propia.

En cuanto contexto socio-territorial del poblador, los relatos permitieron delimitar dos condiciones de su habitar. Por un lado, la vinculación a procesos de migración por violencia [principalmente al noroccidente del Departamento, y en este los municipios de Quinchía y Anserma viejo (Chacón, 2004)]. Por otro, la insatisfacción de necesidades básicas de subsistencia NBI (incluida la vivienda):

Tabla 7. Síntesis de relatos, primer momento, entorno al sujeto habitante

\begin{tabular}{|l|l|}
\hline \multicolumn{1}{|c|}{ Contexto social del sujeto habitante } & Contexto económico del sujeto habitante \\
\hline También llegó a la orilla del río corriéndole & Yo por ejemplo para ganarme la comida me \\
a la violencia en Anserma nuevo (...) es & iba y cargaba agua le llenaba las canequitas \\
que en esa violencia quedamos nosotros & a doña Martha a doña Luisa (...) eran pobres \\
fue llevados (...) mi papa llego acá & igual que nosotros pero tenían comida \\
hermano sin saber qué hacer cuando & nosotros no (...) pa ganarme la comida pa \\
llegamos nosotros aquí a Pereira le & visita, pa mamá y pa mí, me daban un platico \\
tocó dejar las mechitas allá viendo que & de comida a mí y yo ese platico de comida lo \\
teníamos allá una finca la verraquera. & partía pa tres" (Entrevista $1 \_4 ;$ min: $\left.2: 07\right)^{23}$. \\
(Entrevista 2_1; min: $21: 54) 2^{22}$. & \\
\hline
\end{tabular}

Fuente: Elaboración propia.

21 Este es un relato en el que el poblador apela a su memoria histórica sobre las condiciones de subsistencia que tenían cuando recién se empezó a formar el barrio Risaralda.

22 En igual sentido se encuentran los relatos de doña Margarita García: "cuando a nosotros llegamos de Quinchía porque a nosotros nos trajeron pequeñas estaba la violencia metida allá en Quinchía, entonces mi papá fue y vendió la casa" (Entrevista 1_4; min: 13:48). Y de Limbania Pinzón: "En el campo vivíamos nosotros (...) había todo plátano café (...) la familia de mi papá era de Batero (Quinchía) y ya nos sacaron de allá" (Entrevista 5_2; min: 8:31).

23 Relatos como este, donde se define claramente la situación social del poblador se encuentran también en los relatos de la señora Cecilia García; del señor Ancízar Murillo; o la señora Limbania Pinzón. 
Los primeros asentamientos fueron informales; ocupados por pobladores cuyo contexto socioeconómico se encontraba atravesado por la violencia que los expulsó de su territorio originario y por condiciones de insatisfacción de sus necesidades más básicas ${ }^{24}$. Inician así dinámicas de construcción territorial que devienen fricción, desalojos latentes, resistencia, organización, igualmente obtención de acuerdos producidos en la concertación (Ver Relato de don Ancízar Murillo donde da cuenta de la negociación con la familia Aristizábal. Entre- vista 2_1, desde el min: 7: 11). Y con ello la condición económica del territorio que ya empezaba a ser construido; los habitantes del barrio Risaralda pusieron valores a la tierra, negociaron directamente con su propietario y abrieron sendas a la adquisición de títulos "yo creo muchachos que dé a cincuenta pesos por métrico sí (...) toca uno apretar correa pa conseguirse esa plata" (Entrevista 2_1; min: 20:00). Los valores del suelo y de la vivienda como se observa, fueron (y son) un polo de atracción para los más vulnerables.

Tabla 8. Fotografía Ancízar Murillo (entrevistado)

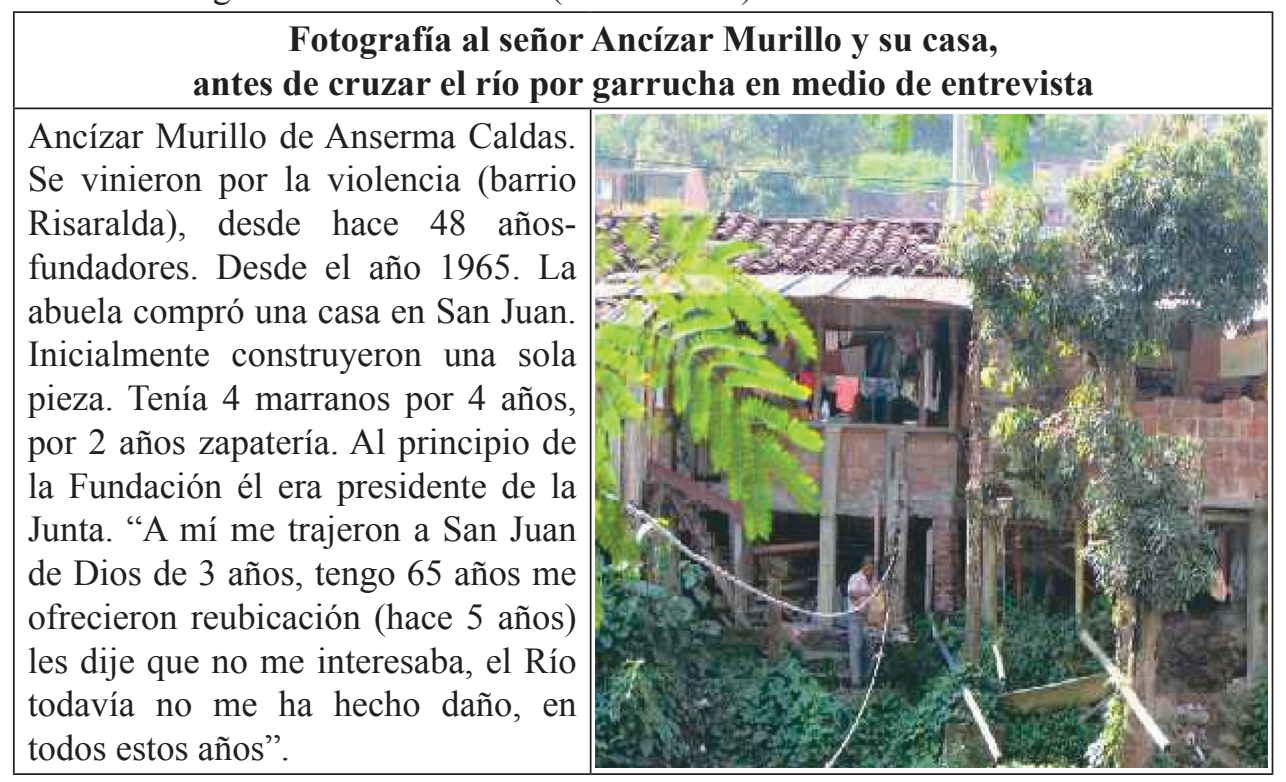

Fuente: Elaboración propia a partir de exploración de campo (2014).

24 A finales de la década de los 40 , debido a un proceso migratorio por motivos de violencia, llegaron a la ciudad personas procedentes del Valle del Cauca, Antioquia, Tolima, y otros Municipios Caldenses. Debido a este proceso migratorio se empezó a poblar la comuna de una forma espontánea, sin planificación e insuficiencia de infraestructura de servicios (Secretaría de Planeación, 2010). 
Momento de toma y apropiación de suelos de protección municipal

Sobre este momento, se enfoca la observación fenomenológica, a períodos más próximos en la dinámica territorial, el momento de toma y posesión de predios, iniciado hacia el 2005 por pobladores que reclaman su inclusión en las políticas públicas de vivienda de la ciudad:

El relato permitió definir así, un contexto físico que a diferencia de lo ocurrido en el momento fundacional, se encuentra proyectado social y económicamente bajo la plataforma funcional que introduce el POT de 2000 para la ciudad (Acuerdos 18 de 2000 y 23 de 2006). Es decir, el territorio físico está articulado y no aislado a la producción social de espacio que la gobernanza ha consolidado bajo las premisas de la sostenibilidad; "Las fuerzas productivas y técnicas permiten intervenir a todos los niveles del espacio: local, regional, nacional, planetario. Se modifica el espacio entero" (Lefebvre 2000, p. 17). Así el sustento físico (que integra el territorio) se incluye al sistema ambiental de protección, al sistema social de espacio público y formalización de la ciudad, y al sistema económico eco-turístico.
El territorio físico por tanto se encuentra en un contexto de transformación donde son otros los propietarios (el municipio), otros los usos del suelo y otras las condiciones del territorio.

De allí se obtienen lecturas del territorio que en términos sociales se sitúa en marginalización, en exclusión social; y en términos económicos un territorio en el que se conservan fuertes inequidades $\mathrm{y}$ necesidades insatisfechas (NBI) (como la vivienda) ${ }^{25}$ (Ver Tabla 9).

A este panorama se suma la condición socioeconómica del poblador que va a ocupar terrenos y su acción política como sujeto habitante. En el marco de vínculos sociales-filiales, llegan al sector, pobladores que ante el vacío y falta de funcionalidad territorial, y dadas sus condiciones sociales de vulnerabilidad, ocupan estos te-

25 "La metodología de NBI busca determinar, si las necesidades básicas de la población se encuentran cubiertas (...) los indicadores seleccionados, son: Viviendas inadecuadas, Viviendas con hacinamiento crítico, Viviendas con servicios inadecuados, Viviendas con alta dependencia económica, Viviendas con niños en edad escolar que no asisten a la escuela". Se debe aclarar que el tratamiento a cada uno de estos indicadores se dá a partir de la información etnográfica; es decir, su trato es cualitativo y se determina a partir de los relatos del habitante. Igualmente se aclara cómo el último indicador no se aborda en la investigación, dada la falta de información etnográfica al no estar referenciada en el diseño de las entrevistas. 
rritorios mediante la construcción de asentamientos informales en lo que anteriormente fueron predios de otros pobladores ya reubicados. (Ver tabla 10).

Tabla 9. Síntesis relatos, segundo momento sobre el territorio

\begin{tabular}{|c|c|}
\hline Condición social del territorio & Condición económica del territorio \\
\hline $\begin{array}{l}\text { "Esto estaba tan pobladito parejito } \\
\text { parejito estaba, pero aquí no, más que } \\
\text { todo en este barrio Risaralda, si quedo } \\
\text { muy descubierto, casi toda la gente se } \\
\text { fue (...) todo eso quedo ahí desocupado } \\
\text { (...) aquí en los lotes vacíos la gente } \\
\text { empezó a meterse se venían aquí de los } \\
\text { barrios aledaños se venían a consumir } \\
\text { drogas aquí (...) y el basurero más } \\
\text { impresionante (...) ya querían volver eso } \\
\text { hay un basurero un metedero de vicio y } \\
\text { uno no podía decir nada" (Entrevista 5_1; } \\
\text { min: } 12: 09 \text { ) }\end{array}$ & $\begin{array}{l}\text { "Con } 150 \text { pesos nos fuimos a buscar } \\
\text { un apartamentico para arrendar (...) } \\
\text { esperemos a ver si conseguimos otra cosa } \\
\text { más favorable...entonces nos vinimos } \\
\text { por los lados de la avenida del río } \\
\text { ¡buscando a ver! resulta que vimos ese } \\
\text { terreno entonces le dije yo a mi señora } \\
\text { ¿será que ahí está nuestra casa será que } \\
\text { nos metemos ahí? (...) ese mismo día } \\
\text { compramos la madera con eso, como ya } \\
\text { le dije empeñamos un televisor, me preste } \\
\text { una plata gota gota y así nos metimos } \\
\text { ahí" (Entrevista } 8 \text { _ } \text {; min: } 1: 33 \text { ) }\end{array}$ \\
\hline
\end{tabular}

Fuente: Elaboración propia.

Tabla 10. Síntesis de relatos, segundo momento sobre el sujeto habitante

\begin{tabular}{|l|l|}
\hline \multicolumn{1}{|c|}{ Condición social del territorio } & \multicolumn{1}{c|}{ Condición económica del territorio } \\
\hline $\begin{array}{l}\text { "(vivió en la casa de la mamá) por mucho } \\
\text { tiempo y de ahí yo conseguí un hogar y } \\
\text { de ahí me toco invadir" (Entrevista 11_1; } \\
\text { min: 1:01) }\end{array}$ & $\begin{array}{l}\text { pobreza absoluta (en referencia a la } \\
\text { reubicación), sin embargo nos vamos para } \\
\text { allá (proyecto de vivienda Salamanca) y } \\
\text { van a ser menos los ingresos y más los } \\
\text { gastos" (Entrevista 9_2; min: 7:50). }\end{array}$ \\
$\begin{array}{l}\text { "(pregunta sobre el por qué llega a la } \\
\text { zona) Por una vivienda para mis hijos" } \\
\text { (Entrevista 12_1; min: 0:28) }\end{array}$ & $\begin{array}{l}\text { "En este país es muy difícil adquirir } \\
\text { vivienda; una vivienda digna, en ese } \\
\text { entonces no habían programas como los } \\
\text { de este momento, yo pagaba arriendo o } \\
\text { vivía de arrimado por ahí mejor dicho de } \\
\text { pagar arriendo, ahí es más fácil porque } \\
\text { ahí nos iban a ayudar supuestamente" } \\
\text { (Entrevista 13_1; min: 0:38) }\end{array}$ \\
\hline
\end{tabular}

Fuente: Elaboración propia. 
La confluencia de momentos de consolidación reflexiva sobre nodales

la política pública territorial que se viene implementando en la ciu-

Plantear un análisis-interpretación dad de Pereira. Esto dado que se al proceso inicial de construcción territorial que el sujeto habitante establece con su lugar (los asentamientos de la orilla del río Otún) desde dos momentos nodales temporalmente distantes, ofreció puntos de confluencia que para los objetivos de esta investigación encuentran similitudes y puntos de confluencia tan idénticos a pesar de las distancias temporales, que es posible establecer vectores de comportamiento en la dialéctica: territorio construido/ política pública territorial. (Tablas 11 y 12). Confluencias:

operaron como base en el camino

Tabla 11. Confluencia de momentos nodales: sujeto habitante

\begin{tabular}{|l|l|}
\hline \multicolumn{2}{|c|}{$\begin{array}{c}\text { Contexto socioeconómico de la población en términos } \\
\text { de vulnerabilidad social a partir de las NBI }\end{array}$} \\
\hline \multicolumn{1}{|c|}{ Momento fundacional } & \multicolumn{1}{|c|}{$\begin{array}{c}\text { Momento de apropiación y } \\
\text { toma de predios }\end{array}$} \\
\hline $\begin{array}{l}\text { Definido por pobladores de origen campesino } \\
\text { expulsados de su territorio original, que } \\
\text { llegan a la ciudad en condiciones de pobreza } \\
\text { y de carencias en la cobertura de sus } \\
\text { principales necesidades básicas. }\end{array}$ & $\begin{array}{l}\text { Mediado por pobladores urbanos } \\
\text { condiciones de pobreza (entendida } \\
\text { como NBI), y sobre estas de trabajo y } \\
\text { vivienda principalmente }\end{array}$ \\
\hline
\end{tabular}

Fuente: Elaboración propia.

Tabla 12. Confluencia de momentos nodales: territorio

Contexto socioeconómico del territorio, en términos de acceso y redes sociales

Condición social del lugar como borde- invasión en el que se hace asequible la consecución de terrenos o vivienda

- Asequible desde el punto de vista económico dados los precios de la tierra o de la vivienda o de los materiales para su construcción;

- Asequible desde el punto de vista social dadas las redes de familiaridad establecidas.

- Manejo que la política pública territorial ha establecido sobre la zona al evidenciarse ausencia efectiva de planes de manejo y sostenibilidad.

Fuente: Elaboración propia. 


\section{Vínculos territoriales}

\section{La casa-refugio}

Explorar fenomenológicamente la territorialidad del sujeto implica abordar sus vínculos más estrechos. En este caso el proporcionado por la casa-refugio entendida desde su obtención como bien tangible, que para el sujeto habitante define desde el punto de vista social protección y amparo Bachelard (1975); desde lo económico estabilidad e ingresos $\mathrm{y}$, desde lo afectivo valores emotivos vinculados al devenir mismo de la territorialidad que la habita.

Tabla 13. Síntesis relatos sobre significados de la casa-refugio

\begin{tabular}{|c|c|c|}
\hline $\begin{array}{c}\text { Casa refugio desde lo } \\
\text { social }\end{array}$ & $\begin{array}{c}\text { Casa refugio desde lo } \\
\text { económico }\end{array}$ & $\begin{array}{c}\text { Casa refugio desde lo } \\
\text { afectivo }\end{array}$ \\
\hline $\begin{array}{l}\text { Eso era todo eso era ya, } \\
\text { esa es mi casa, me faltaba } \\
\text { (...) que tener estabilidad } \\
\text { laboral y ya, ya tengo } \\
\text { casa el sueño de toda } \\
\text { persona (...) y ya mis } \\
\text { hijas también es mi casa } \\
\text { se sentían en su casa (...) } \\
\text { ya se sentía de uno (...) } \\
\text { cada vez aumentando la } \\
\text { construcción. (Entrevista } \\
102 \text { min: } 2: 22)\end{array}$ & $\begin{array}{l}\text { Pa nosotros era todo } \\
\text { porque ahí teníamos el } \\
\text { hogar construido y todo } \\
\text { (...) algo que requiere uno } \\
\text { y necesita para el bienestar } \\
\text { de la familia de uno (...) } \\
\text { aspiraba en el momento } \\
\text { que uno fuera reubicado } \\
\text { para una vivienda nueva } \\
\text { (relato de poblador. } \\
\text { (Entrevista 11_1; min: } \\
5: 46)\end{array}$ & $\begin{array}{l}\text { "por eso es que yo quiero } \\
\text { tanto este racho hermano } \\
\text { aquí nacieron mis hijos } \\
\text { (...) ya la hija mayor tiene } \\
48 \text { años (...) y ella nació } \\
\text { acá". (Entrevista } 2 \text { 1; min: } \\
\text { 15: } 00)\end{array}$ \\
\hline
\end{tabular}

Fuente: Elaboración propia.

En el sentido afectivo cabe destacar relatos como el de la señora Alba Mery Lancheros (pobladora histórica) que deja entrever esa construcción de nido (como casarefugio) que en Bachelard (1975) es cuerpo "tomando su forma desde el interior como una concha, en una intimidad que trabaja físicamente" (p. 135), "casa que es la persona misma, su forma y su esfuerzo inmediato (...) su padecimiento" (p. 135). Dice la señora Lancheros:

Pa mí es un tesoro preciado porque no es solo por amañarme acá sino por ser algo que mi mamá lucho tanto, que mi mamá dejó la vida de ella acá, porque ella misma con su esfuerzo, 
con su lucha ella fue la que construyó (...) pa mí tiene un valor sentimental. (Entrevista 7_1; min: 11:00).

Como se observa, la casa-refugio es fuente esencial de vínculo con el territorio, sobre esta interactúan simbióticamente dimensiones que tienen que ver con la subsistencia misma y con la emotividad subjetiva de quien construye territorio. El sujeto habitante que se territorializa va controlando el espacio y con este los procesos sociales que devienen (Haesbaert, 2013; Fernández, 2009), a partir del posicionamiento de su propio refugio.

\section{Las redes de subsistencia}

Por red se comprende un movimiento progresivo-extensivo, una articulación de pequeñas zonas (Haesbaert, 2013) con múltiples puntos de localización. Entendido como subsistencia, se comprende en el marco de relaciones de producción que establece el sujeto habitante para tratar de dar satisfacción a sus necesidades básicas. Así el sujeto se expande, circula por un territorio más extenso que su casarefugio, generando mayor control de espacio y de procesos sociales en su búsqueda económica. De esta forma los vínculos con el territorio se estrechan al ser fuente de satisfacción de sus propias necesidades, al posibilitar trabajo, capital monetario y capital fijo.

La fenomenología planteada, permitió igualmente visualizar vectores de comportamiento que definen esta variable. De esta forma, las redes de subsistencia han creado estrechos vínculos al territorio que conforman los asentamientos de las orillas del río, en tres sentidos: dada la interacción locacional que esta permite con respecto al clúster Centro (Comuna Centro); dada la búsqueda de fuentes de ingreso en el mercado que se moviliza sobre el mismo lugar; y dada la adquisición de la misma casa-refugio que constituye fuente de ingresos: 
Tabla 14. Síntesis redes de subsistencia

\begin{tabular}{|c|c|c|}
\hline Subsistencia clúster centro & $\begin{array}{l}\text { Subsistencia } \\
\text { mercado local }\end{array}$ & Subsistencia casa refugio \\
\hline $\begin{array}{l}\text { A mí no me gustaría porque } \\
\text { aquí estamos cerquita de } \\
\text { todo, estamos cerquita de los } \\
\text { hospitales, de los colegios } \\
\text { del puesto de salud, usted } \\
\text { si se agrava a media noche } \\
\text { aborda un taxi todo eso } \\
\text { entonces son cosas que a uno } \\
\text { como pobre lo benefician... } \\
\text { es como la gente que tiene } \\
\text { plata se van a vivir a barrios } \\
\text { retirados pero uno no ya uno } \\
\text { se va haciendo viejo y a uno } \\
\text { le dificulta hasta irse por allá. } \\
\text { (Entrevista } 7 \text { 1; min: } 16: 00 \text { ) }\end{array}$ & $\begin{array}{l}\text { Yo fui una de las que } \\
\text { sacó arena del río y } \\
\text { piedra pa vender (...) } \\
\text { anteriormente nosotros } \\
\text { sacábamos volquetadas } \\
\text { de piedra y arena pa } \\
\text { vender. (Entrevista 6_1, } \\
\text { min. 6:28) }\end{array}$ & $\begin{array}{l}\text { Si nos dan eso (en } \\
\text { referencia a una casa de } \\
\text { reubicación) quien nos va } \\
\text { a pagar servicios, póngase } \\
\text { usted a pensar ¡muy bien, } \\
\text { muy bueno! pero quien } \\
\text { nos va a pagar los servicios } \\
\text { (...) dígame a mí ya nadie } \\
\text { me da trabajo no tengo } \\
\text { una pensión, entonces } \\
\text { hermano dígame la única } \\
\text { renta mía es ese arriendito } \\
\text { de ahí y eso cuando les da } \\
\text { la gana (...) (Entrevista } \\
2 \text { 2; min: 5:10) }\end{array}$ \\
\hline
\end{tabular}

Fuente: Elaboración propia.

\section{Una síntesis sobre la territorialidad}

De esta forma, el sujeto habitante va construyendo su territorio, se va enlazando a él, va estableciendo representaciones y significados, estrecha su condición material y social, económica y política. Es sujeto motor del universo social. Bajo la necesidad de subsistir y de tener un refugio domina el medio físico, se apropia de espacios, los empodera; controla relaciones sociales al interior de este (y es controlado por otras), es solidario-contradictorio en el sentido de estas relaciones sociales. Su acción, tanto como sus decisiones y sus visiones del universo social, dependen directamente de su estar en el mundo, de su posición en un territorio, la territorialidad que cotidianamente construye define en gran medida la tensión o la aceptación; el conflicto o la concertación.

Para el sujeto habitante en las márgenes del río, este ha sido su territorio, la posibilidad de subsistir en marcos de inequidad social y marginalización; la posibilidad de refugio y abrigo en medios hostiles o de supervivencia: la margen del río así, no se comprenderá desde el discurso gobernanza del riesgo 
inminente, de la ciudad informal, del asentamiento sub-normal, del riesgo hidrológico (Acuerdo 18, 2000), es margen sustento de la propia existencia, es margen económica y social; igualmente la reubicación y los sistemas estructurantes que atraviesan la zona, no tienen la lectura de inminencia, de necesidad prioritaria, estas políticas de ciudad que se proyecta vocacionalmente (Acuerdo 18, 2000) obedecen a condiciones materiales concretas para el sujeto que deben ser resueltas como fundamento primario de la acción territorializante de la gobernanza.

De allí la importancia de enfocar los relatos; la importancia de la fenomenología sobre la territorialidad. Visto así, un método de inclusión en el desarrollo de visiones geográficas sobre el territorio: el sujeto que habita en la cotidianidad hace parte del mundo de la vida, lo construye, genera discursos sobre este, actúa en él; es a su vez dimensión relegada en la planeación y el ordenamiento, su posición (locacional) obedece a los vaivenes de la política económica y al modelo territorial, su voz necesariamente debe empoderarse, debe consolidarse en las entrañas mismas de la política pública, debe ser actor relevante, correlativo. Así se hace desarrollo sostenible territorial, desde la holística que es transversal al ser y al mundo de la vida.

\section{Conclusiones}

Los caminos abiertos a partir del uso de técnicas como la entrevista, la revisión de documentos y la observación participante, que definieron una exploración de tipo fenomenológica sobre el proceso de territorialización del sujeto habitante (en los barrios Risaralda, San Juan de Dios y Salazar Robledo de la ciudad de Pereira), permitió visualizar:

\section{Frente a los conflictos con la política pública territorial:} Tres elementos; el primero de ellos: situaciones de inestabilidad social para el sujeto que habita y para el territorio que ocupa. Al establecer una serie de programas y acciones sobre territorios definidos por la insatisfacción de sus necesidades básicas, se introducen tensiones que no conjuran estas, al contrario las profundizan (vacíos espaciales, reasentamientos por invasión, tensiones por movilidad, por sostenimiento económico). Segundo, situaciones de inesta- 
bilidad económica: al plantear procesos en los que las redes de subsistencia establecidas por el poblador, se alejan de sus centros de interacción (como sucede en las interacciones con el centro de la ciudad) o de sus mercados más próximos (la misma casa-refugio y el mismo asentamiento). Y por último, ruptura de afectos y emotividades, vinculadas a la territorialidad que se establece desde los primeros momentos de asentamiento y que se enfrenta a programas preestablecidos por la gobernanza, en los que no encuentra cabida la necesidad y la condición del propio sujeto habitante objeto de esta fenomenología.

\section{Frente al sujeto habitante: es} este el principal actor del territorio. Es quien establece interacciones dialécticas (correlativas para los dos momentos nodales abordados), el que se vincula territorialmente tanto desde su condición socioeconómica, como desde el mismo territorio que ocupa. Vinculación material y significativa a partir de la casa-refugio y las redes de subsistencia. Con esto se reconoce la posición del sujeto como "motor de la vida social" que establece acciones-fricción con la política pública territorial: fricción al negarse a abandonar su predio; fricción al reubicarse y regresar extendiendo redes de familiaridad que constituyen la base de nuevos reasentamientos (segundo momento nodal); fricción al apropiar predios, tomarlos para sí y generar acción colectiva que reivindica vivienda digna.

Es el sujeto que genera dinámicas de apropiación y control (territorialidad) desde su condición de desplazado que busca reasentare, o desde su condición de sujeto con condiciones de NBI, sujeto que apropia y controla procesos sociales de crecimiento y expansión urbana, de usos y valor del suelo, de morfologías de ciudad al determinar trazados y arquitecturas espontáneas (informales), procesos sociales de participación al reivindicar sus mismas condiciones de NBI, procesos de visibilización y movilidad política, procesos sociales vinculados a su actividad económica. De ahí que el sujeto objeto de esta fenomenología, proponga dinámicas territoriales de ruptura y fricción, al ser sujeto habitante con condiciones económicas, sociales y emotivas 
concretas que encuentra en la política pública establecida para la ciudad rupturas a su propia territorialidad.

\section{Frente al desarrollo territorial} sostenible: se plantea como escenario inicial de reflexión crítica, la comprensión de una política pública territorial, en el marco del desarrollo territorial sostenible dado que:

a. La dinámica territorial es multidimensional, en este proceso interactúan dinámicas sociales, económicas, políticas, ambientales, normativas, institucionales, emotivas, éticas. Es decir, el territorio es complejo, interactivo, dialéctico, de allí que se deba rebasar los marcos establecidos en la máxima ganancia de conglomerados y grupos económicos dominantes y optar por un desarrollo territorial en el marco de la inclusión, la participación colectiva y la justicia espacial.

b. La dinámica territorial está sujeta a la interacción de múltiples territorialidades, de allí que la cotidianidad y la hegemonía establezcan puntos de fricción-tensión que terminan acrecentando los fenómenos sociales conflictivos. En este marco, es importante diseñar políticas inclusivas de participación ciudadana, que inicia con procesos formativos del mismo sujeto frente a su acción política en el territorio y terminan con confluencias sociales-políticas sobre contextos y vínculos territoriales.

En este marco, el desarrollo territorial sostenible parte del posicionamiento en las orillas del río, de un sujeto político que más allá de su situación de ocupación de riesgo hidrológico o de ocupación de suelos de protección, posicione sus condiciones de existencia que lo hacen ser al interior de un territorio. Un sujeto que en total despliegue de los principios rectores del ordenamiento territorial: participación, solidaridad, equidad territorial, equidad social y equilibrio territorial (Prieto y Luengas, 2011) tome participación activa en la definición de sus condiciones sociales y económicas ante la reubicación, o ante la permanencia en el territorio o ante las posibles alternativas que la multiterritorialidad permite construir. 


\section{Referencias}

Alcaldía de Pereira. (2000). Plan de Ordenamiento Territorial - POT - Acuerdo 18 de 2000.

Alcaldía de Pereira. (2006). Plan de Ordenamiento Territorial - POT - Acuerdo 23 de 2006.

Alcaldía de Pereira. (2009). Plan de Ordenamiento Territorial - POT - Acuerdo 65 de 2009.

Alcaldía de Pereira. (2011). Informe técnico de la estratificación socioeconómico en el municipio de Pereira. Secretaría de Planeación. Recuperado de: http://portal.pereira.gov.co:7778/ publicador/centro-documentacion/estratificacion-2011.pdf

Bachelard, G. (1975). La poética del espacio. México: Fondo de Cultura Económica.

Barón, J. (2002). Las regiones económicas de Colombia: Un análisis de clúster. Documento de Trabajo sobre Economía Regional, (23).

CARDER - Corporación Autónoma Regional de Risaralda. (1998). Por la cual se fijan lineamientos para orientar el desarrollo de las áreas urbanas y de expansión urbana.

CARDER - Corporación Autónoma Regional de Risaralda. (2002). Construcción de un Ordenamiento Territorial para el Desarrollo Sostenible en la Eco Región del Eje Cafetero 2002. Recuperado de: http://www.almamater.edu.co/Publicaciones/Ecorregion_Eje_ Cafetero_Un_Territorio_de_Oportunidades.pdf

CARDER - Corporación Autónoma Regional de Risaralda. (2010). Acuerdo de manejo para el área del Parque Lineal Río Otún. Recuperado de: http://www.carder.gov.co/

CARDER - Corporación Autónoma Regional de Risaralda. (2013). Datos generales de la ciudad de Pereira. Sistema de información ambiental y estadístico (SIAE) Recuperado de http:// siae.carder.gov.co/pereira/pereira-datos-generales

Chacón, M. (2004). Dinámica y determinantes de la violencia durante "la violencia" en Colombia. (Tesis de grado Maestría en Economía, Universidad de Los Andes). Recuperado de: https:// economia.uniandes.edu.co/components/com_booklibrary/ebooks/D2004-16.pdf

Congreso de Colombia. (28 de julio de 1978). Decreto 1541. Por el cual se reglamenta la Parte III del Libro II del Decreto-Ley 2811 de 1974. Recuperado de: http://www.alcaldiabogota. gov.co/sisjur/normas/Norma1.jsp?i=1250

Congreso de Colombia. (18 de julio de 1997). Ley 388. Por la cual se modifica la Ley 9 de 1989 y se dictan otras disposiciones [Ley 388 de 1997]. DO: 43.091. Recuperado de: http://www. alcaldiabogota.gov.co/sisjur/normas/Norma1.jsp?i=339

Contraloría Municipal de Pereira. (2009). Informe del estado de los recursos naturales y del medio ambiente. Vigencia 2008. Recuperado de: http:/www.contraloriapereira.gov.co/ media/informe\%20ambiental/Informe\%20Ambiental\%202008.pdf 
Departamento Administrativo Nacional de Estadística-DANE. (2005). Censo general 2005. Recuperado de: http://www.dane.gov.co/index.php/esp/poblacion-y-registros-vitales/ censos/censo-2005

Feres, M. \& Mancero, J. (2001). El método de las necesidades básicas insatisfechas (NBI) y sus aplicaciones en América Latina. CEPAL/ECLAC. Serie Estudios Estadísticos y Prospectivos, (7).

Fernandes, B. (2009). Sobre a tipologia de territórios. En Territórios e territorialidades: Teorias, processos e conflitos (pp. 197-215). São Paulo: Editora Expressão Popular.

Gutiérrez, F. (2012) Del discurso del desarrollo a la visión territorial sostenible. Perspectiva Geográfica, 17, 233-258.

Haesbaert, R. (2013). Del mito de la desterritorialización a la multiterritorialidad. Cultura y representaciones sociales, 8(15), 9-42. Recuperado de: http://www.scielo.org.mx/scielo. php?script=sci_arttext\&pid=S2007a81102013000200001\&lng=es\&tlng=es

Hernández, N. (2007). Insostenibilidad y Sostenibilidad en el desarrollo de la vivienda informal. En Castillo (Ed.), Procesos urbanos informales y territorio: Ensayos en torno a la construcción de sociedad, territorio y ciudad. Bogotá: Universidad Nacional de Colombia.

Lefebvre, H. (2000). La production de l'espace. París: Anthropos.

Lindón, A. (2000). El enfoque biográfico como aproximación a la identidad personal y la negociación de la conyugalidad. Revista Mexicana de Sociología, 62(1), 101-121.

Lindón, A. (2009). La construcción socioespacial de la ciudad: el sujeto cuerpo y el sujeto sentimiento. Revista Latinoamericana de Estudios sobre Cuerpos, Emociones y Sociedad, $1,6-20$.

Martínez, A. (2010). Planes de desarrollo, derechos humanos y exclusión, Risaralda 1997-2007. Pereira: Universidad Católica de Pereira.

Montañez, G. \& Delgado, M. (1998). Espacio, territorio y región: conceptos básicos para un proyecto nacional. Recuperado de: http://acoge2000.homestead.com/files/Montanez_y_ Delgado._1998.pdf

Pillet, F. (2004). La geografía y las distintas acepciones del espacio geográfico. Investigaciones Geográficas, 34, 141-154.

POMCHA. (2008). Plan de ordenamiento manejo ambiental de la cuenca hidrográfica del Río Otún. Recuperado de: www.carder.gov.co/intradocuments/.../aprestamiento-y-prospectiva

Prieto, B. \& Luengas, E. (2011). La ley orgánica de ordenamiento territorial, como instrumento para la integración del ordenamiento territorial y ambiental. Revista gestión integral en ingeniería neogranadina. $U M N G, 3(2)$. 
Quintana-Peña, A. (2006). Metodología de investigación científica cualitativa. En A. QuintanaPeña \& W. Montgomery (Eds.), Psicología: tópicos de actualidad (pp. 47-84). Lima, Perú: Universidad Nacional Mayor de San Marcos.

Santos, M. (2000). La naturaleza el espacio: técnica y tiempo; razón y emoción. Barcelona: Ariel.

SIGPER - Secretaría operativa de sistemas de información. (2007). Mapa de barrios de la ciudad de Pereira, Informe de análisis de resultados. Recuperado de: http://sigper.pereira.gov.co/

SPM - Secretaría de Planeación Municipal de Pereira. (2010). Diagnóstico Unidad de planificación 7 (Río Otún). Metodología de investigación científica cualitativa.

Zambrano, F. \& Bernard, O. (1993). Ciudad y territorio: el proceso de poblamiento en Colombia. Bogotá: Tercer Mundo Editores.

Recepción:24 de febrero de 2015

Evaluación: 9 de abril de 2015

Aprobación:12 de mayo de 2015 